\title{
Erratum to: Assessment of the sensitizing potency of preservatives with chance of skin contact by the loose-fit coculture-based sensitization assay (LCSA)
}

\author{
Anna Sonnenburg ${ }^{1} \cdot$ Maximilian Schreiner $^{2} \cdot$ Ralf Stahlmann $^{1}$
}

Published online: 12 May 2016

(C) Springer-Verlag Berlin Heidelberg 2016

Erratum to: Arch Toxicol (2015) 89(12):2339-2344

DOI 10.1007/s00204-014-1406-4

In Archives of Toxicology Volume 89, Issue 12, 2015, page 2342 , table 2, it was stated that the $\mathrm{EC}^{2} 0_{\text {vit }}$ for isopropylparaben and isobutylparaben has values of 128.86 and $608.88 \mu \mathrm{mol} / \mathrm{L}$, respectively. However, these values have mistakenly been interchanged. Therefore, the correct $\mathrm{EC} 50_{\text {vit }}$ values are $608.88 \mu \mathrm{mol} / \mathrm{L}$ for isopropylparaben and $128.86 \mu \mathrm{mol} / \mathrm{L}$ for isobutylparaben.

The online version of the original article can be found under doi:10.1007/s00204-014-1406-4.

Anna Sonnenburg

anna.sonnenburg@charite.de

Ralf Stahlmann

ralf.stahlmann@charite.de

1 Institute of Clinical Pharmacology and Toxicology,

Charité - Universitätsmedizin Berlin, Luisenstr. 7,

10117 Berlin, Germany

2 Department of Internal Medicine, Bundeswehr Hospital,

Berlin, Germany 